\title{
Parcerias Universidade - Escola estabelecidas no processo formativo propiciado pelo Programa Observatório da Educação (OBEDUC)
}

\author{
Alianzas Universidad-Escuela establecidas en el proceso formativo \\ proporcionado por el Programa Observatorio de la Educación (OBEDUC) \\ University - School partnerships established in the training process \\ provided by the Observatory of Education Program (OBEDUC)
}

\section{Patrícia Sandalo Pereira*}

(iD): https://orcid.org/0000-0002-7554-0058

\section{Kely Fabrícia Pereira Nogueira**}

(iD): https://orcid.org/0000-0002-1006-0109

\author{
Nickson Moretti Jorge ${ }^{* * *}$
}

(iD): https://orcid.org/0000-0001-9013-7163

Doi: 10.17533/udea.unipluri.18.2.05

Cómo citar este artículo:

Pereira, P. S.; Nogueira, K. F. P; y Jorge, N. M. (2018).Parcerias Universidade - Escola estabelecidas no processo formativo propiciado pelo Programa Observatório da Educação (OBEDUC). Uni-pluriversidad, 18(2),

70-86. https://doi.org/10.17533/udea.unipluri.18.2.05

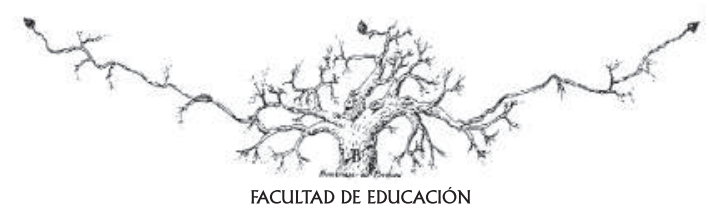

Recibido: 2018-10-14 • Aprobado: 2019-03-10

* Doutora em Educação Matemática (UNESP - Rio Claro). Diretora do Instituto de Matemática e Docente na Universidade Federal de Mato Grosso do Sul (UFMS), Brasil. E-mail: patricia.pereira@ufms.br

** Doutoranda em Educação Matemática pelo Programa de Pós-Graduação em Educação Matemática da Universidade Federal de Mato Grosso do Sul (UFMS). Bolsista FUNDECT. Brasil. E-mail: kelyn230@gmail.com

*** Doutorando em Educação Matemática pelo Programa de Pós-Graduação em Educação Matemática da Universidade Federal de Mato Grosso do Sul (UFMS). Brasil. E-mail: nicksonmoretti@gmail.com 


\section{Resumo}

Este artigo tem por objetivo apresentar alguns resultados do projeto de pesquisa em rede intitulado "Trabalho colaborativo com professores que ensinam Matemática na Educação Básica em escolas públicas das regiões Nordeste e Centro-Oeste", aprovado no Programa Observatório da Educação, financiado pela agência de fomento brasileira Coordenação de Aperfeiçoamento de Pessoal de Nível Superior (Capes) e que foram desenvolvidos no Núcleo da Universidade Federal de Mato Grosso do Sul (UFMS - Brasil), cuja pergunta investigativa foi: Qual o potencial formativo do grupo colaborativo propiciado pelas parcerias entre a Universidade e a Escola? A investigação teve abordagem qualitativa, na qual as dinâmicas dos encontros basearam-se em textos sobre temas que surgiram das falas percebidas nas discussões do grupo. Dessa forma, focalizamos no potencial formativo da parceria propiciada pelo grupo colaborativo, que foi composto pelos professores da Educação Básica, alunos de pós-graduação, alunos de graduação e professores do Ensino Superior. Os resultados apontam indícios das parcerias colaborativas estabelecidas no processo formativo na qual possibilitou visualizar uma postura reflexiva dos profissionais envolvidos.

Palavras-chave: Educação Matemática. Formação de Professores. Colaboração.

\section{Resumen}

Este artículo tiene como objetivo presentar algunos resultados del proyecto de investigación en red titulado: "Trabajo colaborativo con profesores que enseñan matemáticas en educación básica en escuelas públicas en las regiones del Noreste y Midwest", aprobado en el Programa del Observatorio de Educación, financiada por la agencia de promoción brasileña Coordinación de Mejoramiento de Personal de Nivel Superior (CAPES), en el Núcleo de la Universidad Federal de Mato Grosso do Sul (UFMS), cuya cuestión investigadora fue: ¿Cuál es el potencial formativo del grupo colaborativo promovido por las alianzas entre la Universidad y la escuela? La investigación tomó un enfoque cualitativo, en el que la dinámica de las reuniones se basó en textos sobre temas que surgieron de las líneas percibido en las discusiones del grupo. De esta manera, nos centramos en el potencial de formación de las alianzas proporcionada por el grupo de colaboración, que fue compuesta por los profesores de educación básica, estudiantes de posgrado, estudiantes de licenciatura y Profesores de educación superior. Los resultados indican signos de las alianzas colaborativas establecidas en el proceso formativo en el que se ha permitido visualizar una postura reflexiva de los profesionales involucrados.

Palabras clave: Educación matemática. Formación de profesores. Colaboración. 


\begin{abstract}
This article aims to present some results of the network research project entitled "Collaborative work with teachers teaching Mathematics in Basic Education in public schools in the Northeast and Central West regions," approved in the Education Observatory Program, funded by the development agency (Capes), which were developed at the Nucleus of the Federal University of Mato Grosso do Sul (UFMS - Brazil), whose research question was: What is the formative potential of the collaborative group provided by the partnerships between the University and the school? The research had a qualitative approach, in which the dynamics of the meetings were based on texts about themes that emerged from the speeches perceived in the group discussions. In this way, we focus on the formative potential of the partnership provided by the collaborative group, which was composed by the teachers of Basic Education, postgraduate students, undergraduate students and teachers of Higher Education. The results show evidence of the collaborative partnerships established in the training process in which it was possible to visualize a reflexive posture of the professionals involved.
\end{abstract}

Keywords: Mathematics Education. Teacher training. Collaboration. 


\section{Introdução}

No Brasil, o Programa Observatório da Educação (OBEDUC) foi criado enquanto uma política de formação e desenvolvimento profissional de professores da rede pública e foi instituído pelo Decreto Presidencial $n^{\circ}$ 5.803, de 08 de junho de 2006, resultado de uma parceria entre a Coordenação de Aperfeiçoamento de Pessoal de Nível Superior (Capes) e do Instituto Nacional de Estudos e Pesquisas Educacionais Anísio Teixeira (INEP). Teve como finalidade fomentar a produção acadêmica e a formação de recursos pós-graduados em educação, em nível de mestrado e doutorado, por meio de financiamento específico.

A Diretora de Formação de Professores da Educação Básica, durante a realização do $4^{\circ}$ Seminário do Programa Observatório da Educação (OBEDUC), que aconteceu nos dias 27 e 28 de novembro de 2013, na Capes, em Brasília-DF, afirmou: "Queremos ter na Capes uma política de estado de formação de professores sólida, que englobe formação inicial; formação continuada e extensão e formação em pesquisa e divulgação científica" (Disponível em: <http://www. capes.gov.br/educacaobasica/observatorioda-educacao $>$. Acesso em 16 janeiro 2014).
Os dados apresentados neste artigo são alguns resultados do projeto de pesquisa intitulado "Trabalho colaborativo com professores que ensinam Matemática na Educação Básica em escolas públicas das regiões Nordeste e Centro-Oeste", aprovado no Programa Observatório da Educação, financiado pela agência de fomento brasileira Capes.

$\mathrm{O}$ referido projeto foi em rede e contou com a participação de três Instituições do Ensino Superior: Universidade Federal do Mato Grosso do Sul (UFMS), Universidade Federal de Alagoas (UFAL) e Universidade Estadual da Paraíba (UEPB).

Salientamos que no Núcleo UFMS, o projeto foi vinculado ao Grupo de Pesquisa FORMEM - Formação e Educação Matemática, que tem como linha de pesquisa Formação de Professores, cujo objetivo é investigar sobre a formação docente em seus diferentes espaços e níveis educativos.

Desse modo, o objetivo deste artigo é apresentar alguns resultados cujo foco foi o potencial formativo do grupo colaborativo no Núcleo da UFMS propiciado a partir das parcerias entre a Universidade e a Escola.

\section{A parceria Universidade - Escola}

Pensar no processo formativo dos profissionais do magistério da Educação Básica de Matemática - licenciandos e professores -, com base na Resolução $n^{0}$ 2, de 1 de julho de 2015 e no Parecer do Conselho Nacional de Educação (CNE) / Conselho Pleno (CP) $n^{\circ} 2 / 2015$, significa acreditar que deve existir uma parceria entre a Universidade e a Escola Básica.

Corroboramos com Silva (2017), quando afirma que:

[...] a escola e a universidade são instituições dedicadas em promover o 
avanço do conhecimento, da educação e da sociedade, e que são espaços que buscam a construção de saberes e proporcionam a pesquisa. (Silva, 2017, p. 8)

Tomando como base esses dois espaços, vamos discorrer sobre a parceria estabelecida entre essas instituições, na qual vislumbramos possibilidades de um processo formativo que confluam em trabalhos integrados, favorecidos por ações que podem ser desencadeadas pelo movimento da pesquisa colaborativa (Ibiapina; Bandeira; Araújo, 2016).

No Parecer CNE/CP 2/2015, há uma ênfase na "articulação entre educação superior e Educação Básica e regime de colaboração" (Brasil, 2015, p. 4), o qual podemos inferir que está se reportando a existência de uma parceria.

Segundo Foerste (2005), a parceria entre Universidade e Escola Básica, é um tema recente nas pesquisas. $\mathrm{O}$ autor esclarece que no contexto brasileiro, [...] "são poucos os estudos específicos até o momento sobre essa questão. Já na literatura internacional, estão disponíveis produções acadêmicas desde a primeira metade dos anos de 1990, a respeito da temática". (Foerste, 2005, p.1). $\mathrm{O}$ autor também sinaliza que a "parceria na formação dos profissionais do ensino enquanto uma prática de colaboração construída na interface entre universidade e professores da Escola Básica" (Foerste, 2005, p.8) é de grande importância para a profissão docente.

No entanto, corroboramos com Nóvoa (2013) quando afirma que:

Nada será conseguido se não se alterarem as condições existentes nas escolas e as políticas públicas em relação aos professores. É inútil apelar à reflexão se não houver uma organização das escolas que a facilite. É inútil reivindicar uma formação mútua, interpares, colaborativa, se a definição das carreiras docentes não for coerente com este propósito. É inútil propor uma qualificação baseada na investigação e parcerias entre escolas e instituições universitárias, se os normativos legais persistirem em dificultar esta aproximação. (Nóvoa, 2013, p. 206)

Mediante tal afirmação, Clark (1988), descreve que a Universidade e Escola Básica podem se tornar parceiras nesse processo de formação, desde que se entenda que:

Elas se desenvolverão e florescerão apenas se criadas e sustentadas por educadores que estão dispostos e são capazes de encontrar recompensas pessoais na satisfação dos autointeresses dos outros com os quais estão trabalhando. As parcerias serão de valor apenas quando todas as partes procurarem usá-la para a reforma e renovação simultâneas tanto das escolas como das universidades. (Clark, 1988, p. 62)

O autor afirma ainda que não existirá parcerias, se essas forem motivadas pelo interesse dos envolvidos em se autopromoverem ou fugirem das burocracias do sistema escolar.

Segundo Nóvoa (2015, p. 270) "precisamos reinventar a pesquisa como uma práxis coletiva aberta e colaborativa", ou seja, para se conseguir que isso aconteça é necessário partir de um estudo que visa à articulação e a aproximação da escola com a instituição formadora, que é a Universidade.

Corroborando com essa ideia, Maldaner (2003) pontua que existem algumas 
condições iniciais que possibilitam essa parceria, na perspectiva de colaboração:

I) que haja professores disponíveis e motivados para iniciar um trabalho reflexivo conjunto e dispostos a conquistar o tempo e local adequados para fazê-los;

II) que a produção científicotecnológica se dê sobre a atividade dos professores, sobre as suas práticas e seu conhecimento na ação, sendo as teorias pedagógicas a referência e não o fim;

III) que os meios e os fins sejam definidos e redefinidos constantemente no processo e de dentro do grupo;

IV) que haja compromisso de cada membro com o grupo;

V) que a pesquisa do professor sobre a sua atividade se torne, com o tempo, parte integrante de sua atividade profissional e se justifique primeiro para dentro do contexto da situação e, secundariamente, para outras esferas;

\section{$[\ldots]$}

VII) que os professores universitários envolvidos tenham experiência com os problemas concretos das escolas e consigam atuar dentro do componente curricular objeto de mudança, que pode ser interdisciplinar ou de disciplina única.

(Maldaner, 2013, p.11)

Neste sentido, ao pensarmos que profissionais do magistério da Educação Básica de Matemática queremos formar e para qual modelo educativo, Mizukami (2012) traz contribuições importantes no sentido de delimitação de algumas direções e frentes de investimento para esses processos, dentre os quais queremos evidenciar:
[...] A natureza individual e coletiva da aprendizagem profissional da docência;

A escola considerada como local de aprendizagem profissional; [...]

A importância de diferentes tipos de saberes construídos ao longo das trajetórias profissionais, a partir tanto de conhecimento acadêmico/científico quanto da prática pedagógica;

A importância da prática profissional para a construção de conhecimentos próprios da docência e de diferentes naturezas; $[. .$.

A consideração da reflexão como orientação conceitual e fonte de aprendizagem profissional; [...]

A necessidade de tempo e espaço mental para que professores possam se desenvolver profissionalmente; [...]

A importância de construir culturas escolares colaborativas a fim de fazer face à complexidade da mudança; [...]

A necessidade de se contar com a adesão dos professores a programas de desenvolvimento profissional: via de regra eles se engajam em tais programas à procura de novas informações.

(Mizukami, 2012, p.3)

Mediante a todas essas ponderações, o Parecer CNE/CP 2/2015 pontua que a formação de profissionais do magistério da Educação Básica tem se constituído em campo de disputas de concepções, dinâmicas, políticas, currículos, entre outros.

Imbernón (2011) destaca que o empenho em entender como o professor desenvolvese profissionalmente, tem mostrado o foco nas pesquisas sobre a formação inicial e continuada, com intuito de entender e 
mudar concepções de formação que não favorecem o desenvolvimento e acrescenta que "formar professores na mudança e para a mudança por meio do desenvolvimento de capacidades reflexivas em grupo, é abrir caminho para uma verdadeira autonomia compartilhada" (Imbernón, 2011, p.15).

Neste sentido, Zeichner (2010) sugere que esse aperfeiçoamento seja dado entre a articulação Universidade e Escola Básica, enfatizando que a

[...] criação de espaços híbridos na formação de professores no qual o conhecimento empírico e acadêmico e o conhecimento que existe nas comunidades estão juntos de modos menos hierárquicos a serviço da aprendizagem docente (Zeichner, 2010, p.208).

O autor aponta como caminho o rompimento das dicotomias presentes na educação, dentre elas: teoria e prática, professor e aluno, pesquisa e extensão, conteúdo e método. $\mathrm{O}$ que implicaria na construção de espaços, que possam possibilitar o desenvolvimento dos processos de formação inicial ou continuada, de modo que os profissionais do magistério da Educação Básica de Matemática possam adquirir ou aperfeiçoar seus conhecimentos, considerando tanto o conhecimento acadêmico como o conhecimento prático na promoção da aprendizagem profissional da docência.

Scheid, Soares e Flores (2009) apresentam três aspectos positivos, em relação à aproximação desses espaços Universidade e Escola Básica -, são eles:

A inserção de acadêmicos na escola de Educação Básica é de grande valia para os mesmos, considerando que lhes possibilita entrar em contato com a realidade escolar, dinamizando sua formação profissionalizante inicial construindo uma postura docente crítica em constante transformação;

Para os professores já em exercício, oportuniza a formação continuada, pois ao interagir com o mundo acadêmico, aperfeiçoam sua atuação no ensino; e

Para a escola e a sociedade, representa uma alternativa de melhoria da educação que poderá garantir a formação de cidadãos com uma educação científica adequada aos desafios atuais.

(Scheid; Soares; Flores, 2009, p.72).

Diante do exposto, podemos perceber que tais espaços podem permitir a construção e partilha de conhecimentos, que sejam de interesse tanto da universidade quanto da Escola Básica.

Neste sentido, faz-se necessário compreender a formação dos profissionais do magistério da educação "na perspectiva social e alçada ao nível da política pública, tratada como direito, superando o estágio das iniciativas individuais para aperfeiçoamento próprio, por meio da articulação entre formação inicial e continuada [...]" (Brasil, 2015, p.8).

Retomando o Parecer CNE/CP 2/2015, na perspectiva de encaminhar diretrizes conjuntas para a formação inicial e continuada dos profissionais do magistério da Educação Básica, vamos destacar alguns pontos que consideramos importantes, são eles:

[...]; 5) a necessidade de articular as Diretrizes Curriculares Nacionais para a Formação Inicial e Continuada, em Nível Superior, e as Diretrizes Curriculares Nacionais para a Educação Básica; 
6) os princípios que norteiam a base comum nacional para a formação inicial e continuada, tais como: a) sólida formação teórica e interdisciplinar; b) unidade teoria-prática; c) trabalho coletivo e interdisciplinar; d) compromisso social e valorização do profissional da educação [...];

7) a articulação entre graduação e pós-graduação e entre pesquisa e extensão como princípio pedagógico essencial ao exercício e aprimoramento do profissional do magistério e da prática educativa;

8) à docência como ação educativa e como processo pedagógico intencional e metódico, envolvendo conhecimentos específicos, interdisciplinares e pedagógicos, conceitos, princípios e objetivos da formação que se desenvolvem na socialização e construção de conhecimentos, no diálogo constante entre diferentes visões de mundo; $[\ldots]$;

10) a realidade concreta dos sujeitos que dão vida ao currículo e às instituições de Educação Básica, sua organização e gestão, os projetos e cursos de formação, devem ser contextualizados no espaço [...] bem como, possibilitar a compreensão e reflexão sobre as relações entre a vida, o conhecimento, a cultura, o profissional do magistério, o estudante e a instituição; [...];

13) o trabalho coletivo; [...].

(Brasil, 2015, p.22)

Tal documento ainda reafirma como princípios da formação inicial e continuada, alguns pontos que são de grande relevância e merecem destaque,
[...]; III - a colaboração constante entre os entes federados na consecução dos objetivos da Política Nacional de Formação de Profissionais do Magistério da Educação Básica, articulada entre o Ministério da Educação (MEC), as instituições formadoras e os sistemas e redes de ensino;

IV - a garantia de padrão de qualidade dos cursos de formação de docentes ofertados pelas instituições formadoras nas modalidades presencial e à distância;

V - a articulação entre a teoria e a prática no processo de formação docente, fundada no domínio de conhecimentos científicos e didáticos, contemplando a indissociabilidade entre ensino, pesquisa e extensão;

VI - o reconhecimento das instituições de Educação Básica como espaços necessários à formação inicial dos profissionais do magistério;

VII - a importância do projeto formativo nas instituições de educação que reflita a especificidade da formação docente, assegurando organicidade ao trabalho das diferentes unidades que concorrem para essa formação e garantindo sólida base teórica e interdisciplinar;

VIII - a equidade no acesso à formação inicial e continuada, contribuindo para a redução das desigualdades sociais, regionais e locais;

IX - a articulação entre formação inicial e formação continuada, bem como entre os diferentes níveis e modalidades de Educação Básica; [...].

(Brasil, 2015, p.23)

Com este olhar, autores como Contreras (2012), Imbernón (2011), Pimenta e Ghedin (2010), e Libâneo (2010) argumentam 
que a formação inicial e continuada dos professores deve possibilitar a aproximação dos diferentes conhecimentos necessários para sua atuação profissional.

Fiorentini (2005), Boavida e Ponte (2002) destacam que os projetos entre universidade e escolas, a construção coletiva dos saberes docentes, a reflexão sobre a prática, a realidade educativa e social, tem contribuído para o processo de formação profissional ligado à docência.

$\mathrm{Na}$ próxima seção apresentamos a metodologia de Pesquisa Colaborativa, bem como os caminhos percorridos no desenvolvimento da pesquisa no Núcleo UFMS.

\section{Os caminhos da pesquisa}

\subsection{Pesquisa Colaborativa}

A escolha dessa metodologia se deve ao fato de que esse tipo de pesquisa tem visto o professor não como um objeto a ser estudado, mas como um agente ativo, que possui a possibilidade de refletir e mudar a sua prática, por meio dos novos significados os quais atribui a sua prática durante as atividades de coprodução, de conhecimento pelo diálogo e por meio do trabalho colaborativo.

A pesquisa colaborativa promove rupturas com as práticas tradicionais de investigação, tendo os professores como participantes desse processo, de modo que eles não são copesquisadores, mas tomam as decisões e as responsabilidades pelas ações que o grupo desenvolve em conjunto, objetivando transformar uma realidade.

Ibiapina (2016, p. 33) define pesquisa colaborativa, como:

[...] uma atividade de co-produção desenvolvida por pesquisadores e professores, com objetivo de transformar uma determinada realidade educativa, levando tempo para ser concretizada, pelas suas ações serem realizadas em ações formativas, buscando a valorização do pensamento do próximo na construção dos diálogos de autonomia e respeito mútuo.

Conforme aponta Ibiapina (2016, 2012, 2008), a pesquisa colaborativa busca sensibilizar os professores, desenvolvendo neles um processo de reflexão sobre o seu trabalho. Conforme aponta a autora, esta perspectiva proporciona aos envolvidos uma compreensão do micro e do macro social. E, é este potencial que "dá mais poder aos indivíduos para que eles compreendam, analisem e mudem essas realidades, desvelando as ideologias existentes nas relações mantidas no cotidiano escolar e na sociedade". (Ibiapina, 2008, p. 27).

Em conformidade com a autora, a pesquisa colaborativa constitui-se na relação de coprodução entre professores e pesquisadores, na interatividade dos saberes, de formação, de reflexão e desenvolvimento da prática profissional, com a intenção de modificar o cotidiano escolar. A autora reconhece que leva tempo para a consolidação desse empreendimento, uma vez que as propostas de formação continuada, as quais os professores do Ensino Básico participam, têm se preocupado somente em como ensinar, como fazer, sem discutir o "por quê?" e o "para quê?" se ensina. 
Durante o desenvolvimento da pesquisa colaborativa, o pesquisador deve promover ciclos de estudos e reflexão que proporcionem ao professor a motivação necessária para expressar seus pensamentos e as suas práticas docentes.

Com o propósito de articular algumas diretrizes para o desenvolvimento de pesquisas colaborativas, Ibiapina (2016) propõe que,

[...] para a concretização de processos efetivos de investigação que partam dessa abordagem, entre outros aspectos, destaco a sensibilização dos colaboradores, a negociação dos espaços e tempos, o diagnóstico das necessidades formativas e dos conhecimentos prévios, as sessões de estudo intercalados pelos ciclos de reflexão interpessoal e intrapessoal de análises das práticas docentes (Ibiapina, 2016, p.38).

A autora também sugere alguns dispositivos mediadores para $\mathrm{o}$ desenvolvimento da reflexão crítica: as narrativas autobiográficas, a observação colaborativa, as entrevistas coletivas, a videoformação, as sessões reflexivas, dentre outros. Estes dispositivos têm em comum, o construir "informações que tornam observável e verbalizável a prática pedagógica de professores" (Ibiapina, 2008, p. 76).

\subsection{O desenvolvimento da pesquisa no Núcleo UFMS}

Neste trabalho, devem ser voluntários a participação e o envolvimento dos integrantes. Sendo assim, para a escolha de tais integrantes, firmamos uma parceria com professores da Educação Básica que manifestaram interesse na participação de projetos que fossem desenvolvidos pelos professores pertencentes ao Programa de Pós-Graduação.

O grupo constituído no Núcleo da UFMS foi formado por 16 integrantes, sendo eles: uma professora universitária (coordenadora institucional), estudantes de pós-graduação (mestrado acadêmico), estudantes de graduação (Licenciatura em Matemática) e professores da Educação Básica (rede pública). Os encontros foram realizados quinzenalmente na sala do Laboratório do Grupo de Pesquisa FORMEM, na unidade VII da Universidade Federal do Mato Grosso do Sul. Os encontros do grupo no Núcleo UFMS, oportunizaram aos integrantes compartilhar um pouco de si.

As dinâmicas dos encontros basearam-se em textos sobre temas que surgiram das falas percebidas durante as discussões do grupo. O objetivo foi criar um contexto favorável, no qual a parceria entre os professores e futuros professores oportunizasse vivenciar características culturais inerentes a uma reflexão e compreensão da relação existente entre o seu subjetivo e a realidade estabelecida pelos padrões culturais.

Com este propósito, estabelecemos parcerias para realização de um trabalho colaborativo no Núcleo UFMS, possibilitando aos integrantes um desenvolvimento profissional para a melhoria das suas práticas pedagógicas e profissionais. Essa formação representa uma nova perspectiva de desenvolvimento profissional, pois os integrantes desse projeto têm autonomia no desenvolvimento do trabalho numa relação de colaboração. Para Boavida e Ponte (2002), para que haja esse trabalho colaborativo, a confiança, o respeito mútuo e o diálogo são pontos essenciais nesse processo. 
Espaços de formação de trabalho conjunto entre professores da Educação Básica, mestrandos e licenciandos proporcionam aos futuros professores socializações com os alunos da Educação Básica e com professores mais bem preparados e motivados, de modo a contribuir no início de seu percurso profissional, pois já vivenciaram o convívio com a comunidade escolar. Também, nesse contexto, as angústias e as incertezas são partilhadas e discutidas, buscando ajuda e apoio mútuo, de modo que o empenho de todos possa levar os alunos ao sucesso no seu aprendizado.

Para desenvolver este trabalho, estabelecemos uma relação de modo a haver o respeito mútuo, a confiança e o diálogo, conduzindo cada participante a conversar, negociar e analisar as situações envolvidas na comunidade escolar.
As dinâmicas dos encontros basearamse em textos sobre temas que surgiram das falas percebidas nas discussões do grupo. Os dados foram coletados durante os encontros por meio de entrevistas com os participantes do grupo colaborativo, os quais foram videografadas, e uma das unidades de análise emergente foi a "reflexão".

Com isso, a capacidade de reflexão de cada integrante foi importante para análise do grupo, pois observamos as diversas formas de postura reflexiva profissional, tentando compreender as ideias e as atitudes adquiridas no decorrer do desenvolvimento das parcerias colaborativas do trabalho no grupo.

A seguir, serão apresentados alguns resultados da pesquisa evidenciando uma contribuição no desenvolvimento da postura profissional reflexiva dos professores.

\section{Alguns resultados}

Em nossas reuniões foi possível constar que os professores da Educação Básica e os licenciandos indicaram sua concepção sobre formação de professores e sublinharam que esta devia ser pautada na troca de experiências entre os pares, pois assim oportunizaria o aprender uns com outros, conforme podemos observar nos fragmentos elencados a seguir.

[...]porque as experiências partilhadas em nossos encontros e as práticas que faremos serão em conjunto com pessoas que estão em níveis superiores a nós e, por isso, estarão nos ensinando coisas extraclasse, não apenas as matérias da faculdade, mas as matérias da vida de um professor, de um pesquisador, de pessoas que amam o que fazem com a Matemática. (Licencianda E)
[...] aprendi até agora com o projeto, que para a minha vida profissional de professor, é necessário aprender a ouvir, aprender a buscar a unidade dentro da escola e quando eu for trabalhar, aprender que não somos professores sozinhos, tudo conta, o ambiente escolar tem que ser um todo que trabalha junto, todos juntos por uma educação escolar melhor. (Licencianda E)

[...] o projeto representa uma oportunidade de me envolver com os assuntos que permeiam a realidade dos professores de Matemática, oportunidade de colaborar com as práticas pedagógicas e desenvolver pesquisas referentes a essas práticas. (Licencianda C)

$\begin{array}{cccr}{[\ldots]} & \text { visualizar } & \text { as } & \text { questões } \\ \text { enfrentadas } & \text { pelos } & & \text { professores }\end{array}$


atualmente nas escolas públicas, os problemas que envolvem tanto o ensino quanto as ferramentas utilizadas para ensinar. Dessa forma, esse projeto está contribuindo no fato de possibilitar a troca de experiências, tornando o curso de Licenciatura em Matemática mais próximo da realidade enfrentada pelo professor. (Licencianda C)

Construir um profissional da educação, que para entender as relações extremamente complexas, que envolvem o social e o educacional, é necessário para isso, juntar e discutir as ideias coletivas. Logo, o professor dentro da sua própria ação age como educador reflexivo e pesquisador, já que para ele lhe é dado vários atributos, fomentando a transformação social. (Professor C)

Os fragmentos apresentados das falas dos integrantes do grupo não deixam de ser uma afirmação do quanto é sério para eles, o trabalho que está sendo proposto no projeto e de quanto é importante participar efetivamente nas reuniões, onde é propiciada aos integrantes reflexões sobre as suas práticas docentes.

Conforme Pimenta, Garrido e Moura (2010), a reflexão da prática docente deve ser pautada pelas teorias da educação, visto que ela fornecerá aportes teóricos para o professor desenvolver uma reflexão na ação e sobre a ação que, de fato, caminha para mudança. Assim, como já foi descrito, nas reuniões do grupo são propostas leituras que contribuem para o professor questionar sua própria prática.

Baseando-nos nas falas dos licenciandos e dos professores integrantes deste grupo, no projeto desenvolvido no Núcleo UFMS, concordamos com Sousa (2013), quando diz que este projeto proporciona aos seus parceiros um desenvolvimento profissional, por investir na formação inicial e continuada deles.

Nesta proposição, a parceria fica explícita quando observamos alguns recortes das falas dos professores, conforme apresentado a seguir.

[...] assim o objetivo maior da parceria aqui estabelecida, é a questão do crescimento profissional de cada um e a questão emancipatória, você ter autonomia de falar e de pensar, [...] tem reflexão, para ter reflexão entre nós, temos que ter a colaboração. (sic) (Professor C)

[...] reunindo com as meninas da graduação para preparar, trazer ideias, discutir, preparar material, preparar uma aula, aplicar e verificar o que deu certo e o que poderia melhorar, qual é a dificuldade, se é problema de organização na sala de aula, relatar problemas que surgiram, eu acredito que essa unidade dá certo $[\ldots]$ (sic) (Professor D)

Assim, podemos perceber conforme Pimenta e Ghedin (2010), que este momento de compartilhamento de ideias, contribui tanto para os licenciandos como para os professores repensar tanto a teoria como refletir sobre a sua prática.

Os professores também trouxeram suas angústias para a troca de experiências entre os pares. Esse fato oportuniza o aprender uns com outros, como podemos observar nos relatos apresentados a seguir.

[...] até mesmo eu como professor numa sala de aula, buscar soluções para os problemas cotidianos na ação, aplicar e desenvolver, ver se deu certo, reformular e ir aplicando, quando trazemos para o grupo, podemos ver se estamos certos ou o que podemos melhorar com a ajuda do outro [...] (sic) (Professor C). 
Você aplica o trabalho, o conteúdo, volta, reavalia, quando você avalia os alunos, você avalia o que você fez, aquilo que você ensinou, a maneira que você expôs o conteúdo e daí ou você dá continuidade ou muda, aborda de outra forma ou outra estratégia. Eu creio que seria isso. Não usei palavras teóricas, mas falei o que penso. (sic) (Professor D)

Colaboração implica negociação dos conflitos e são inerentes ao processo de ensino e aprendizagem. (sic) (Licencianda A)

Os fragmentos apresentados das falas dos integrantes do grupo demonstraram o quanto é importante, para eles, o trabalho proposto no projeto, proporcionando a cada participante uma reflexão das práticas docentes.

O trabalho colaborativo deve ser desenvolvido visando à parceria entre os integrantes a favor do desenvolvimento da aprendizagem. Os alunos da graduação têm que se mobilizar colaborativamente com o professor na aplicação das ações desenvolvidas pelo grupo, pois quando observam a teoria na prática conseguem perceber quão importante é a investigação e de quantos meios ela pode contribuir para a reflexão no processo formativo.

Assim, durante a ajuda mútua entre os integrantes do grupo, e após algumas reuniões, percebemos nas falas dos professores da Educação Básica e dos licenciandos, a importância da parceria estabelecida no projeto desenvolvido no Núcleo UFMS.

[...] a parceria estabelecida via projeto auxilia a minha formação profissional, possibilitando reconhecer as questões enfrentadas pelos professores atualmente nas escolas públicas e os problemas que envolvem tanto o ensino, quanto as ferramentas utilizadas para ensinar. Dessa forma, esse projeto está contribuindo com a troca de experiências, tornando o curso de Licenciatura em Matemática mais próximo da realidade enfrentada pelo professor. (sic) (Licencianda B)

[...] o grupo é formado por graduandos, mestrandos e professores da Educação Básica, o que traz possibilidades de me fazer crescer no conhecimento, para que no futuro eu seja uma boa professora de Matemática no ensino regular. Além disso, esse contato consequentemente me deixa mais próxima da realidade na educação das escolas. (sic) (Licencianda A)

Sendo assim, pelas falas apresentadas anteriormente, pudemos perceber a importância da parceria colaborativa estabelecida no projeto, pois propiciou aos integrantes refletir sobre as suas práticas docentes, a qual se caracteriza como um sistema vivo em que o respeito mútuo, a tolerância e a confiança são essenciais no processo de coprodução de conhecimento (Ibiapina, 2016; Pereira, Sakai, Nogueira, 2018). Essa parceria vide pesquisa colaborativa pressupõe: interação entre pesquisa e formação. Sua fundamentação epistemológica e sociológica é incorporar a competência prática e reflexiva do sujeito em sua conjuntura (Ferreira, 2007).

Admitimos, no entanto que mesmo quando o professor, em formação e em exercício, trabalham como parceiros, evidenciam que

[...] não há igualdade absoluta, uma vez que ambos trazem diferentes conhecimentos para a colaboração, mas há paridade no relacionamento e cada um reconhece e respeita as contribuições do outro (Zeichner, 2010, p. 222, grifo nosso). 
Em suma, a inserção de acadêmicos na escola de Educação Básica é de grande valia na sua formação inicial, pois ao entrarem em contato com a realidade escolar, estão dinamizando sua formação profissionalizante, construindo uma postura docente crítica e, em constante transformação.

\section{Concluindo}

No artigo apresentamos indícios que as parcerias estabelecidas entre os integrantes durante o desenvolvimento do projeto no Núcleo UFMS, pode revelar o potencial formativo propiciado pelo grupo colaborativo. Esse potencial formativo se dá a partir da reestruturação de ideias adequadas quando compartilham uns com os outros, necessidades e conflitos, negociam as ideias e as práticas, potencializam as suas vidas pessoais e profissionais. Esse movimento ocorre sempre em via de mão dupla: pesquisadores e docentes colaboram no processo de pesquisa e formação, que se torna reflexivo, crítico, interpretativo e explicativo dos seus atos com a finalidade de sua reelaboração.

No entanto, salientamos que a parceria colaborativa (Ibiapina, 2016) estabelecida entre a universidade e a escola, contudo não poderá se resumir apenas na inserção dos licenciandos nesse ambiente, propício para a melhoria da formação de professores. É preciso também, aproximar a escola da universidade, pois é nessa instância, que se produz o conhecimento científico em relação à prática pedagógica. É também, a partir da universidade, que se irradia o conhecimento construído nas áreas do conhecimento.

Posto isto, percebemos a relevância do Programa Observatório da Educação por meio do projeto desenvolvido, o qual propiciou uma parceria colaborativa que possibilitou a real aproximação da escola ao ambiente de excelência na produção de saberes, no qual criou condições para que os sujeitos partícipes, e as instituições estabeleçam negociações concretas, construam o conhecimento ao partilharem reflexivamente ideações, respeitando os interesses específicos, discutindo e interferindo no discurso dos outros, vislumbrando uma real conexão entre universidade/escola.

Ressaltamos ainda que, só foi possível isso, devido à estrutura proposta pelo Programa OBEDUC, a qual une professores e pesquisadores em formação juntamente com os professores em exercício da Educação Básica, para juntos desenvolverem pesquisas.

Salientamos também, que a opção de desenvolver o projeto no Núcleo UFMS, utilizando a pesquisa colaborativa como referencial teórico e metodológico (Ibiapina, 2016, 2012, 2008), contribuiu imensamente, pois permitiu que os integrantes tomassem as decisões e fossem responsáveis pelas ações que o grupo desenvolveu em conjunto, objetivando transformar a realidade. Realidade esta, posta como materialização para a Educação Básica.

Os resultados apontam indícios das parcerias colaborativas estabelecidas no processo formativo na qual possibilitou visualizar uma postura reflexiva dos profissionais envolvidos. Neste viés, corroboramos com Silva Júnior (2010) 
quando enfatiza que formar professores para a Educação Básica constitui, antes de mais nada, adotar a própria educação básica como lócus de estudo. Ao fazê-lo, teremos que considerar os valores que explicitem o sentido da vida humana, ou seja, os direitos de inserção nos bens sociais e culturais. Posto assim, o Programa OBEDUC, nos possibilitou esse movimento, e para além como afirmam Pereira, Sakai e Nogueira (2018)

[...] como alternativas para a compreensão dessas relações, professores de diferentes níveis de ensino têm se voltado aos processos de pesquisa e formação, nos mais diversos contextos: escolas, instituições de ensino superior, programas de pós-graduação, grupos de estudos, dentre outros (Pereira; Sakai; Nogueira, 2018, p. 6).

Destarte, a inserção dos licenciandos na escola de Educação Básica e demais espaços formativos são de grande relevância, considerando que lhes possibilita entrar em contato com a realidade escolar, sensibilizando a formação inicial; para os professores já em exercício, oportuniza a formação continuada, pois ao interagir com o mundo acadêmico, aperfeiçoam sua atuação no ensino; e para a escola e a sociedade, representa uma alternativa de melhoria da educação que poderá garantir a formação de cidadãos com uma educação científica adequada aos desafios da atualidade.

Com esses entendimentos, Pereira, Sakai e Nogueira (2018) nos chamam a atenção, quanto à complexidade dos atos conscientes realizados entre as relações dos professores dos diferentes níveis, reforçando a necessidade de compreendemos que a complexidade torna-se inerente à natureza da prática docente, de modo que a educação no sentido macro não é somente a humanização, mas também a socialização.

\section{REFERÊNCIAS BIBLIOGRÁFICAS}

Boavida, A. M.; Ponte, J. P. (2002). Investigação Colaborativa: potencialidades e problemas. In: GTI (Org.) Reflectir e investigar sobre a prática profissional. Lisboa: APM, pp. 43 - 55.

Brasil. (2015). Conselho Nacional de Educação. Conselho Pleno. Parecer CNE/CP 2/2015. Diretrizes Curriculares Nacionais para a Formação Inicial e Continuada dos Profissionais do Magistério da Educação Básica. Diário Oficial da União, Brasília, 25 de junho de 2015, Seção 1, pp. 13.

Brasil. (2015). Conselho Nacional de Educação. Conselho Pleno. Resolução CNE/CP 2/2015. Define as Diretrizes Curriculares Nacionais para a Formação Inicial em nível superior (cursos de licenciatura, cursos de formação pedagógica para graduados e cursos de segunda licenciatura) e para a formação continuada. Diário Oficial da União, Brasília, 02 de julho de 2015, Seção 1, pp. 08-12.

Contreras, J. (2012) A autonomia de professores. Trad. Sandra Trabucco Valenzuella. São Paulo: Cortez. 
Clark, R. (1988). School-University Relationships: An Interpretative Review. In: Sirotnik, K.; Goodlad, J. (Eds). School-University Partnerships in Action: Concepts, Cases and Concerns. (pp. 32-65). New York: Teachers College Press.

Ferreira, A. L. (2007). Possibilidade e realismo crítico da Pesquisa e da Formação: a colaboração entre pesquisadores e professores. In: Ibiapina, I. M. L. M; Ribeiro, M. M. G; Ferreira, M. S. Pesquisa em Educação: Múltiplos olhares. (pp. 13-27). Brasília: Líber Livro Editor.

Fiorentini, D. (2005). A formação matemática e didático-pedagógica nas disciplinas da licenciatura em matemática. Revista de Educação da PUC-Campinas. Campinas, (18), pp. 107-115.

Foerste, E. (2004). Parceria na formação de professores. Revista Iberoamericana de Educación. OEIOrganização dos Estados Ibero-Americano, 1-12.

Ibiapina, I. M. L. M. (2016). Reflexões sobre a produção do campo teórico-metodológico das pesquisas colaborativas: gênese e expansão. In: Ibiapina, I. M. L. M.; Bandeira, H. M. M.; Araújo, F. A. M. Pesquisa Colaborativa: multirreferenciais e práticas convergentes. Teresina: EDUFPI, v. 1, 33-62.

Ibiapina, I. M. L. M. (2012). Pesquisa Colaborativa: atividade de investigação e formação no Grupo Formar. In: Ibiapina, I. M. L. M.; Lima, G. S. B.; Carvalho, M. V. C. Pesquisa em Educação: múltiplos referenciais e suas práticas. Teresina: EDUFPI, v. 1, 175-184.

Ibiapina, I. M. L. M. (2008). Pesquisa colaborativa: investigação, formação e produção de conhecimentos. Brasília: Líber Livro Editora, 2008.

Ibiapina, I. M. L. M.; Bandeira, H. M. M.; Araújo, F. A. M. (2016). Pesquisa Colaborativa: multirreferenciais e práticas convergentes. Teresina: EDUFPI.

Imbernón, F. (2011). Formação docente profissional: formar-se para a mudança e a incerteza. 9 ed. São Paulo: Cortez.

Libâneo, J. C. (2010). Reflexividade e formação de professores: outra oscilação do pensamento pedagógico brasileiro. In: Pimenta, S. G.; Ghedin, E. (Orgs.) Professor Reflexivo no Brasil: gênese e crítica de um conceito. (pp. 53-79). São Paulo: Cortez.

Maldaner, O. A. (2003). A formação inicial e continuada de professores de Química: professores/ pesquisadores. 2. ed., Ijuí: Unijuí. 424p. (Coleção Educação em Química).

Mizukami, M. G. N. (2012). Desenvolvimento profissional da docência centrado na escola: pesquisa e prática envolvendo universidade pública. Anais do XVI Endipe-Encontro Nacional de Didática e Práticas de Ensino. Unicamp, Campinas, Livro 3, p. 253-267.

Nóvoa, A. (2015). Em busca da liberdade nas universidades: para que serve a pesquisa em educação. Educação \& Pesquisa, v. 41(1), 263-272.

Nóvoa, A. (2013). Nada substitui um bom professor: propostas para uma revolução no campo da formação de professores. In: Gatti, B. A.; Silva Júnior, C. A.; Nicoletti, M. G.; Pagotto, M. D. S. (Orgs.). Por uma política de formação de professores. São Paulo: Editora da UNESP. 199-210. 
Pereira, P. S.; Sakai, E. C. T.; Nogueira, K. F, P. (2018). Colaboração: uma ação para legitimar as pesquisas da própria prática de professores de Matemática. Cadernos Cenpec. v. 8,(1), 05-28.

Pimenta, S. G.; Ghedin, E. (2010). Professor Reflexivo no Brasil: gênese e crítica de um conceito, 7. ed. São Paulo: Cortez.

Pimenta, S. G.; Garrido, E.; Moura, M. O. (2010). Professor Reflexivo: Construindo Uma Crítica. In: Pimenta, S.G.; Ghedin, E. (Orgs.) Professor Reflexivo no Brasil: gênese e crítica de um conceito. (pp. 17-52). São Paulo: Cortez.

Ponte, J. P. (1995). Perspectivas de desenvolvimento profissional de professores de Matemática. In: Ponte, J. P.; Monteiro, C.; Maia, M.; Serrazina, L.; Loureiro, C. (Eds.). Desenvolvimento profissional de professores de Matemática: Que formação? (pp. 193-211). Lisboa: SPCE.

Scheid, N. M. J.; Soares, B. M.; Flores, M. L. T. (2009). Universidade e Escola Básica: uma importante parceria para o aprimoramento da educação científica. Revista Brasileira de Ensino de Ciência e Tecnologia, Ponta Grossa - PR, 2(2), 01-11.

Silva, M. R. (2017). Articulação Escola e Universidade: algumas reflexões acerca da formação inicial e continuada para professores da educação básica. Anais. $38^{\mathrm{a}}$ Reunião Nacional da ANPEd. UFMA, São Luís/MA, 01-15.

Silva Júnior, C. A. (2010). Fortalecimento das politicas de valorização docente: proposição de novos formatos para cursos de licenciatura para o estado da Bahia. Brasília, DF: UNESCO/ CAPES, 2010. (Relatório. Documento interno).

Sousa, M. C. (2013). Parcerias compartilhadas entre Universidades e Escolas na formação de professores. Anais do XI Encontro Nacional de Educação Matemática, Curitiba - PR.

Zeichner, K. M. (2010). Para além da divisão entre professor-pesquisador e pesquisador acadêmico. In: Geraldi, C. M. G.; Fiorentini, D.; Pereira, E. M. A. (Orgs). Cartografias do trabalho docente: professor(a)-pesquisador(a). (pp. 207-236). Campinas, SP: Mercado de Letras. 